\title{
VALUE OF EXTENT OF HIPPOCAMPAL RESECTION IN THE SURGICAL TREATMENT OF TEMPORAL LOBE EPILEPSY
}

\author{
Leonardo Bonilha, Eliane Kobayashi, João Paulo V. Mattos, \\ Donizete C. Honorato, Li M. Li, Fernando Cendes
}

\begin{abstract}
Objective: Unilateral hippocampal atrophy is indicator of good surgical prognosis in patients with temporal lobe epilepsy (TLE). Some patients however do not become seizure free after surgery. We assessed if the extent of hippocampal and amygdala resection is associated with outcome. Methods: Thirty patients with TLE with unilateral or clearly asymmetric hippocampal atrophy who underwent surgical treatment were evaluated concerning preoperative clinical variables and interictal EEG abnormalities. Amygdala and hippocampal resection was evaluated by post-operative MRI. We compared seizure free versus non-seizure free patients, and patients with good outcome (Engel's classes I and II) versus patients with poor outcome. Results: There was significant association between the extent of hippocampal resection and the outcome. Pre-operative variables and interictal EEG abnormalities did not show relationship with outcome as documented in previous studies. Conclusion: The extent of hippocampal resection is associated with outcome. Incomplete resection of atrophic hippocampus may explain most surgical failures in patients with TLE due to unilateral hippocampal sclerosis.
\end{abstract}

KEY WORDS: temporal lobe epilepsy, epilepsy surgery, interictal EEG.

\section{Valor da extensão da ressecção do hipocampo no tratamento cirúrgico da epilepsia de lobo temporal}

RESUMO - Objetivo: A atrofia hipocampal unilateral é indicadora de bom prognóstico cirúrgico em pacientes com epilepsia do lobo temporal (ELT). Alguns pacientes, no entanto, não se tornam livres de crises após a cirurgia. Nós avaliamos se i) o EEG interictal e ii) a extensão da ressecção do hipocampo e da amígdala estão associados com resultado cirúrgico. Método: Trinta pacientes com ELT com atrofia hipocampal unilateral ou claramente assimétrica que se submeteram a tratamento cirúrgico foram avaliados quanto a variáveis clínicas pré-operatórias e anormalidades ao EEG interictal. A ressecção da amídala e do hipocampo foi avaliada pela ressonância magnética pós-operatória. Nós comparamos os pacientes livres de crises com os pacientes não livres de crises, e os pacientes com bom resultado cirúrgico (classes I e II de Engel) com os pacientes com resultado cirúrgico ruim. Resultados: Houve associação significativa entre a extensão da ressecção do hipocampo e o resultado cirúrgico. As variáveis pré-operatórias e o EEG interictal não mostraram associação significativa com o resultado cirúrgico como demonstrado em outros estudos. Conclusão: Houve associação entre a extensão de ressecção do hipocampo e o resultado cirúrgico. Ressecção incompleta do hipocampo atrófico pode explicar a maior parte das falhas no tratamento cirúrgico de pacientes com ELT devido à esclerose hipocampal unilateral.

PALAVRAS-CHAVE: epilepsia do lobo temporal, cirurgia para epilepsia, EEG interictal.

Anterior temporal lobe removal is a well established form of treatment for patients with drugresistant temporal lobe epilepsy (TLE) ${ }^{1,2}$. More than $80 \%$ of these patients become seizure free or almost seizure free after the surgery. Mesial temporal lobe sclerosis (MTS) is the most common postoperative pathologic finding in patients with $\mathrm{TLE}^{3-6}$ and nowadays MTS can be diagnosed in vivo by high resolution magnetic resonance imaging (MRI) in most patients ${ }^{7-9}$. Hippocampal atrophy, associated or not with hyperintense T2 signal, is the most important MRI feature of MTS an it can reliably be assessed by careful visual analysis and by computed assisted volumetric measurements ${ }^{2,8-10}$.

Neuroimage Laboratory, Neurology Department, State University of Campinas (UNICAMP), Campinas SP, Brazil.

Received 20 June 2003, received in final form 8 August 2003. Accepted 12 September 2003.

Dr. Fernando Cendes - Department of Neurology, FCM, UNICAMP - Caixa Pastal 6111 - 13081-970 Campinas SP - Brasil. E-mail: fcendes@unicamp.br 
The degree of hippocampal atrophy correlates with the severity of the pathology $7,9,11$ and outcome after surgery ${ }^{8,10,12-15}$. The presence of unilateral hippocampal atrophy or very asymmetric hippocampi, determined by high resolution MRI, indicates a good surgical prognosis. However, it is still not clear why some of these patients fail to achieve good seizure outcome ${ }^{13,16}$.

We studied a series of patients with medically refractory TLE and hippocampal atrophy who underwent surgical treatment. All patients were submitted to postoperative MRI evaluation. The purpose of this study was to determine if the extent of hippocampal and amygdala resection is associated with outcome.

\section{METHOD}

We selected 30 patients with TLE and clear-cut unilateral or very asymmetric hippocampal atrophy determined by visual analysis. None of these patients had other types of lesion on high resolution MRI. We tabulated current patient age, gender, associated risk factors, age of onset, history of febrile seizures and EEG findings.

EEG investigation - Interictal epileptiform abnormalities, defined as sharp waves or focal spikes over the temporal lobe regions were determined by routine scalp EEGs using the International 10-20 system with zygomatic electrodes and prolonged EEG recordings during wakefulness. EEG findings were classified as (1) unilateral, if more than $90 \%$ of the epileptiform discharges occurred in one side, or (2) bilateral if otherwise.

MRI visual analysis - All patients had T1 and T2 weighted MRI, obtained in 3 orthogonal planes. Temporal lobe structures were analyzed in T1-weighted inversion recovery (IR) and T2-weighted 3mm thickness coronal images, obtained perpendicular to the long axis of the hippocampi ${ }^{17}$.

Temporal lobe structures were evaluated for the following criteria: a) atrophy of the anterior portion of the temporal lobe; b) asymmetry of the temporal horns of the lateral ventricles; c) hyperintense $\mathrm{T} 2$ signal of the medial temporal structures; d) abnormality of the internal structure of the hippocampus and e) hippocampal atrophy.

Hippocampal atrophy was defined when one hippocampus was clearly smaller than the contralateral hippocampus in more than 3 coronal cross-sections associated with abnormal format, usually a flattened shape. In most patients these findings were associated with hyperintense $\mathrm{T} 2$ signal and loss of internal structures on IR images ${ }^{18}$.

The extent of the amygdala and hippocampal resection was qualitatively evaluated by visual analysis of post-operative T1 MRI images in the sagittal and coronal planes. The amygdala resection was defined as total, partial or null. The total resection implicates the removal of the amygdala in its rostro-caudal extension, observed in the sagittal plane, and the removal of the superior portion above the line connecting the endorhinal sulcus and the inferior portion of the circular sulcus of the insulae, observed in the sagittal plane.

The partial resection denotes the persistence of remnants of the amygdala in its rostro-caudal extension, or resection of the superior border below the line connecting the endorhinal sulcus and the inferior portion of the circular sulcus of the insulae. The null resection was defined when the amygdala appeared completely preserved (Figs 1 and 2).

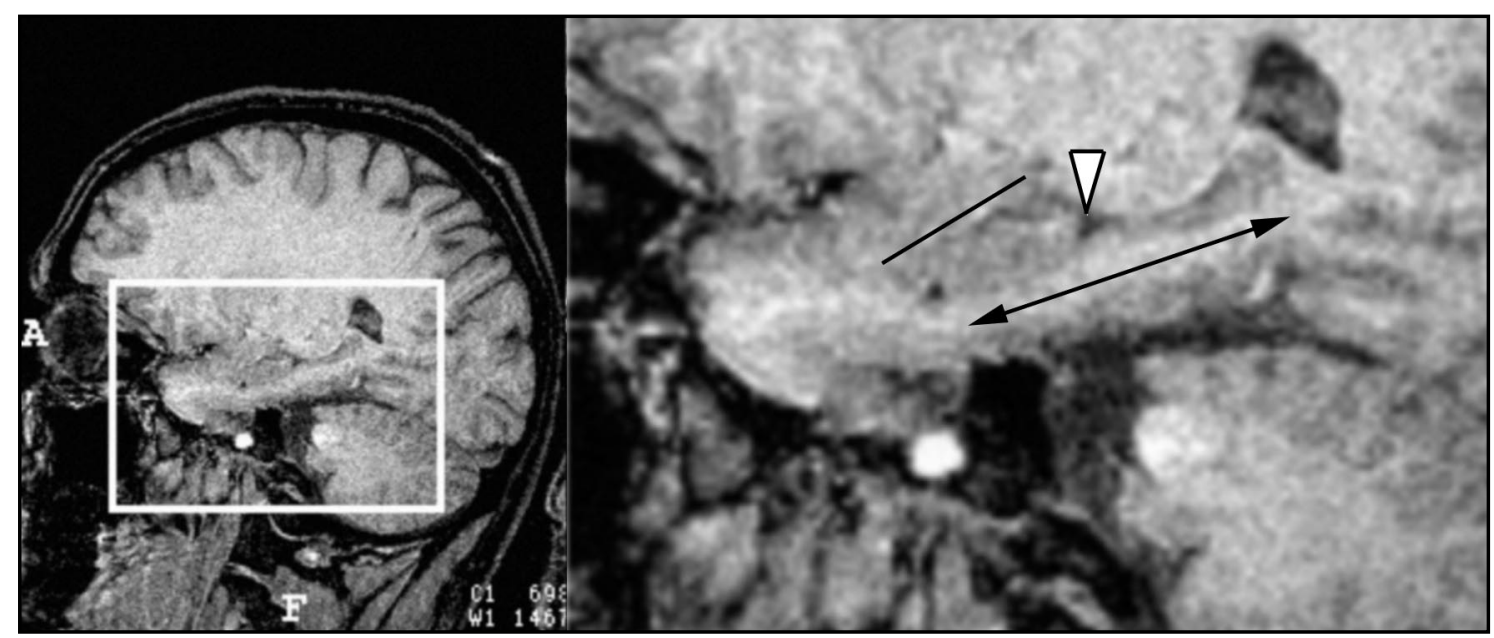

Fig 1. Sagittal T1 weighted MRI images of a normal subject showing, in the left image, the hippocampal region (white box) which is magnified in the right image. In the right image, the double-headed arrow located inferiorly to the hippocampus represents the rostro-caudal extension of the hippocampus while the arrow head represents the intralimbic gyrus, and the line located within the amygdala represents the rostro-caudal extension of the amygdala. 


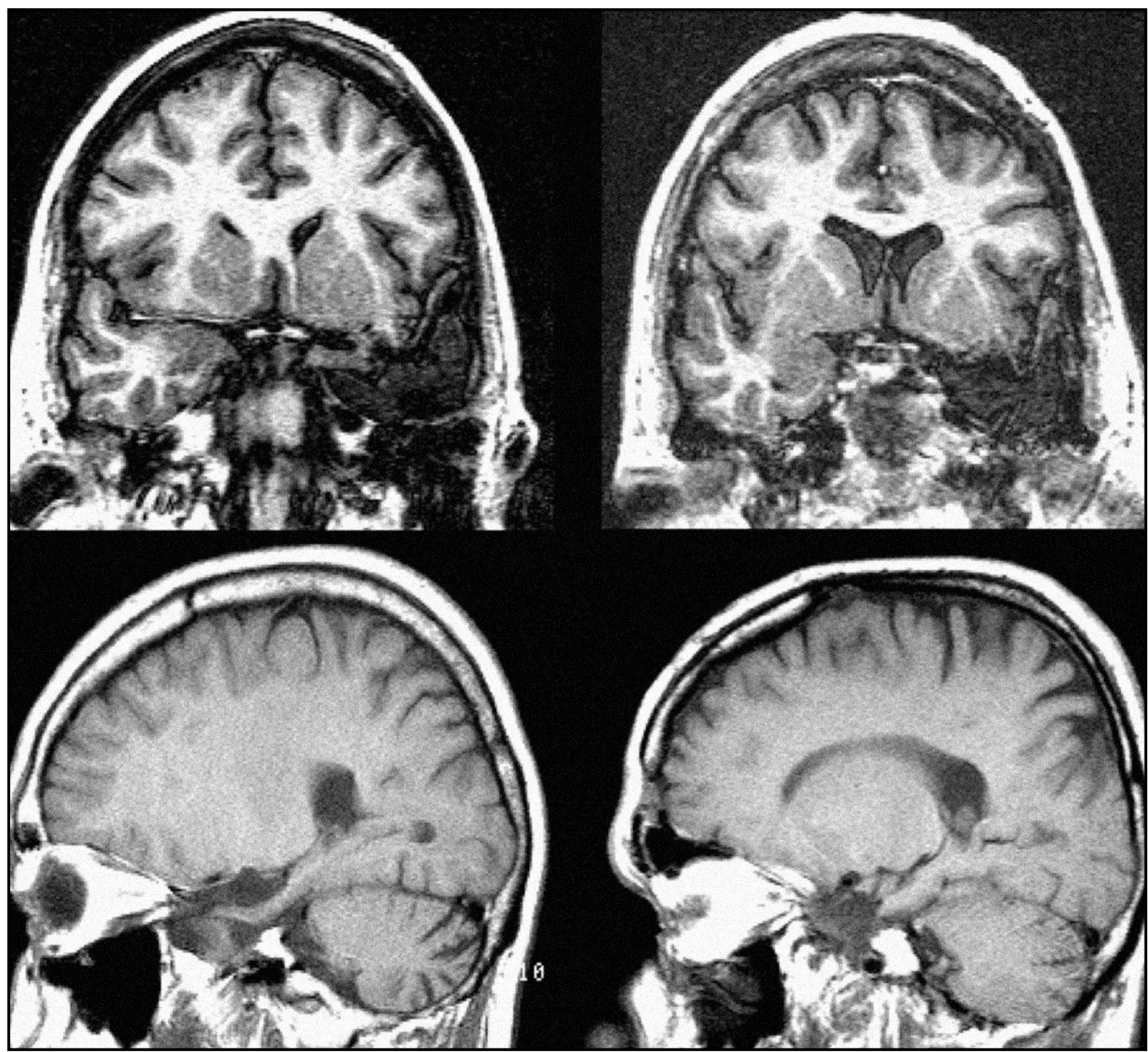

Fig 2. Composite of MRI images showing different extensions of hippocampal and amygdala resection. The top images show IR post-operative MRI coronal images. The top left image shows a partial left amygdala resection and the top right image shows a complete left amygdala resection. The bottom images show $T 1$ weighted post-operative MRI sagittal images. The left image shows a posterior incomplete resection of the hippocampus and the right image shows an anterior incomplete resection.

The surgical resection of the hippocampus was defined as following: 1 . Null resection- when the hippocampus appeared completely preserved. 2 . Incomplete resection of the anterior portion of the hippocampus when the resection involved the anterior portion of the hippocampus but did not extend up to the intralimbic gyrus. 3. Complete resection of the anterior portion of the hippocampus - when the hippocampus anterior to the intralimbic gyrus was completely removed and the extension involved up to the intralimbic gyrus. 4. Complete resection of the anterior portion and incomplete resection of the posterior portion of the hippocampus - when the body of the hippocampus posterior to the intralimbic gyrus was incompletely removed.

Surgical outcome - Postoperative seizure control was evaluated based on a detailed history and neurological examination performed on follow-up visits to the Epilepsy Clinics of the University Hospital of the
State University of Campinas - UNICAMP. Post-surgical outcome was determined using Engel's classification1: Class I - seizure-free; Class II - rare seizures, with a maximum of 3 seizures a year; Class III - worthwhile improvement, with a reduction of more than $90 \%$ of seizures; Class IV - no worthwhile improvement $(<90 \%$ reduction in seizure frequency).

Statistical evaluation - For statistical analysis, patients were grouped according to the surgical outcome in two groups: a) seizure-free (Class I) and b) not seizure-free (Classes II-IV). We also performed the statistical analysis with the patients grouped according to the surgical results in two groups: a) good outcome (Classes I and II) and b) unsatisfactory outcome (Classes III and IV).

Chi-square or Fisher's exact test was used to compare the two groups on data obtained for each of the preoperative parameters: age, time of symptoms; associated risk factors (neurocysticercosis, trauma and en- 
cephalitis); history of febrile seizures; associated atrophy of the temporal lobe; and EEG abnormalities (unilateral versus bilateral interictal abnormalities). Chisquare or Fisher's exact test was also used to compare the extent of the surgical resection of the amygdala and the hippocampus independently with the outcome

\section{RESULTS}

Thirty patients ( 20 women), with a mean age of 38 (26 to 55 years), were included in this study. They were followed with a mean postoperative time of 46 months ( 28 to 59 months). The age of seizure onset ranged from 2 to 32 years (mean = 10 years) and mean duration of seizure disorder was 28 years (range from 12 to 48 ).

\section{Surgical outcome}

Sixteen patients (53\%) were in Class I outcome, 9 in Class II (30\%), and 5 (17\%) in Class III. Twentyfive patients $(83 \%)$ had good outcome (seizure free or almost seizure free status after surgery). One patient was in class IV outcome after an incomplete hippocampal removal and after re-operation he (or she) has been on class II outcome.

All patients underwent postoperative MRI to assess the extent of surgical resection. Seventeen patients $(57 \%)$ had no identifiable risk factors. Evidence of neurocysticercosis on CT scan was observed in 11 patients (37\%) and history of head trauma in none. Three patients $(10 \%)$ had history of febrile seizures in childhood.

EEG showed bilateral interictal epileptiform abnormalities in 11 patients (37\%) and unilateral epileptiform discharges in 19 patients (63\%).

All patients had unilateral or very asymmetric hippocampal atrophy. Twelve patients had additional ipsilateral temporal lobe atrophy, and 3 $(10 \%)$ had bilateral temporal lobe atrophy.

All patients underwent anterior temporal lobe resection plus amygdalo-hippocampectomy ipsilateral to side of hippocampal atrophy or predominant atrophy. Two patients $(7 \%)$ had null resection of the amygdala, 20 (66\%) had partial resection and $8(27 \%)$ had complete resection. Three patients $(10 \%)$ had null resection of the hippocampus, $11(37 \%)$ had incomplete resection of the anterior portion of the hippocampus, 10 (33\%) had complete resection of the anterior portion without resection of the posterior portion and $6(20 \%)$ had complete resection of the anterior portion with partial resection of the posterior portion.

Only one patient was submitted to a second operation to expand the extension of the hippocampal resection. The first surgery resulted in incomplete anterior resection of the hippocampus and the second surgery expanded the resection to complete anterior resection. This patient improved her outcome from Engel's class IV to Engel's class II, after the second surgery. Only the data from this patient's first surgery was taken into account for the statistical analysis performed in this study.

There were no differences between the groups of seizure free versus not seizure-free in proportion of gender, history of risk factor, history of febrile seizures and atrophy of the anterior temporal lobe. There was not statistically significant difference between these two groups in the frequency of bilateral interictal EEG abnormalities.

The comparison of the two groups classified according to good or unsatisfactory outcome also failed to reveal differences between the proportion of gender, history of risk factor, history of febrile seizures, atrophy of the anterior temporal lobe, atrophy of the contralateral hippocampus and frequency of bilateral interictal EEG abnormalities.

The extent of amygdala resection did not correlate with the outcome. Conversely, the extent of hippocampal resection showed significant association with the good outcome $(p<0.001)$ and seizure-free outcome $(p<0.001)$.

\section{DISCUSSION}

The understanding of how some presurgical clinical findings can affect the postoperative outcome is crucial to enable a better indication of the surgical intervention. This may also be taken into account to arrive at a prognostic statement regarding the surgical outcome for individual patients ${ }^{1,19}$. It is well known that surgical outcome in partial epilepsies is related to the pathological substrate and the possibility of completely removing the abnormal brain tissue ${ }^{1,8,10,13,19-21}$. The presence, degree and bilaterality of hippocampal atrophy is capable of predicting with accuracy the result of the surgery in patients with TLE $10,12,13,22,23$. Complete or almost complete seizure control (classes I and II of Engel) can be obtained in approximately $90 \%$ or more of the TLE patients with unilateral atrophy, while patients with bilateral atrophy or normal hippocampi have a much worse outcome ${ }^{8,12,13,15}$.

Different from previous studies of surgical 
outcome in TLE that included different profiles of hippocampal pathology 1,8,10,12-15,19-24, here we included a subgroup of patients with TLE with unilateral or clearly asymmetric hippocampal atrophy. We wanted to assess why some patients in this subgroup, who are expected to have the best surgical results, fail to achieve seizure control postoperatively. For that, we analyzed a number of variables that are routinely assessed in the preoperative evaluation of patients with TLE to determine if any of these variables could have surgical prognostic value in TLE patients with unilateral hippocampal atrophy. We also analyzed whether the extension of hippocampal removal correlates with the postoperative control of seizures.

The sample used in this study does not reflect the overall surgical outcome. Conversely, since the inclusion criteria involved the presence of postoperative MRI, we evaluated a great number of patients who achieved suboptimal seizure control postoperatively. This allowed the comparison of the variables that may influence outcome in this group, i. e., patients with TLE and unilateral or very asymmetrical hippocampal atrophy.

None of the clinical parameters analyzed were statistically different between the groups of patients who became seizure free and those who continued having seizures after the surgery. The presence of bilateral interictal epileptiform abnormalities, which could indicate bilateral hippocampal pathology, did not show significant relationship with failure to achieve complete postoperative seizure control.

Some functional or structural abnormalities can be subtle enough not to be detected by conventional MRI visual analysis, and the non-resected pathological tissue can be responsible to the persistence of seizures after the surgery. Therefore, the detection of more widespread structural or functional abnormalities in patients with TLE could help to predict surgical results. This could be accomplished with the pre-surgical clinical evaluation. However, the variables that we studied failed to correlate with prognosis. Moreover, the presence of interictal EEG abnormalities, albeit presumably indicating bilateral temporal lobe pathology, does not indicate poor surgical control. It remains to be determined if these variables may influence surgical outcome in a group of patients who had practically the same amount of tissue resected.
The extent of hippocampal resection, in turn, was significantly associated with outcome. This means that despite variability in the clinical preoperative variables assessed, the most striking determinant of persistence of seizures after the surgery, in our group, is the size of the non-resected hippocampus.

Previous reports have correlated the extent of hippocampal removal with seizure control ${ }^{25,26}$, and there is evidence of seizure activity with origin in the posterior portion of the hippocampus ${ }^{27}$ and in the amygdala ${ }^{28}$. However there is not a consensus regarding the standard amount of resection and some centers present excellent outcome with surgery tailored on electrocorticography results, with limited amount of resection ${ }^{29}$. Moreover, the effect of the epileptogenic activity of the non-resected tissue of the temporal lobe, especially the parahippocampal gyrus, is yet to be discovered. Further studies addressing to the comparison of outcome and the extension of the hippocampus and perihippocampal tissue resection should be performed by careful quantitative analysis of the temporal lobe.

\section{REFERENCES}

1. Engel J Jr. Outcome with respect to epileptic seizures. In Engel J Jr., (ED). Surgical treatment of the epilepsies. New York: Raven Press, 1987:553-571.

2. Engel J Jr, Cascino GD, Shields WD. Surgically remediable syndromes. In Engel J Jr., Peddley TA (EDS). Epilepsy: a comprehensive textbook. Philadelphia: Lippincott-Raven, 1997:1687-1696.

3. Gloor P. Mesial temporal sclerosis: historical background and an overview from a modern perspective. In Luders H (ED). Epilepsy surgery. New York: Raven Press, 1991:689-703.

4. Barbosa-Coutinho LM, Hilbig A, Calcagnotto ME, et al. [Neuropathology of hard to control epilepsy. Study of 300 consecutive cases]. Arq Neuropsiquiatr 1999;57:405-414.

5. Margerison JH, Corselis JAN. Epilepsy and the temporal lobes: a clinical electroencephalographic and neuropathological study of the brain in epilepsy, with particular reference to the temporal lobes. Brain 1966;89:499-530.

6. Meencke HJ, Veith G. Hippocampal sclerosis in epilepsy. In Luders H, (ED). Epilepsy surgery. New York: Raven Press, 1991:705-715.

7. Cascino GD, Jack CR, Parisi JE, et al. Magnetic resonance imaging-based volume studies in temporal lobe epilepsy: pathological correlations. Ann Neurol 1991;30:31-36.

8. Jack CR, Jr., Sharbrough FW, Cascino GD, Hirschorn KA, O'Brien PC, Marsh WR. Magnetic resonance image-based hippocampal volumetry: correlation with outcome after temporal lobectomy. Ann Neurol 1992;31:138-146.

9. Watson C, Jack CR, Jr., Cendes F. Volumetric magnetic resonance imaging. Clinical applications and contributions to the understanding of temporal lobe epilepsy. Arch Neurol 1997;54:1521-1531.

10. Kuzniecky R, Burgard S, Faught E, Morawetz R, Bartolucci A. Predictive value of magnetic resonance imaging in temporal lobe epilepsy surgery. Arch Neurol 1993;50:65-69.

11. Cendes F, Andermann F, Gloor P, et al. MRI volumetric measurements of amygdala and hippocampus in temporal lobe epilepsy. Neurology 1993;43:719-725.

12. Arruda F, Cendes F, Andermann F, et al. Mesial atrophy and outcome after amygdalohippocampectomy or temporal lobe removal. Ann Neurol 1996;40:446-450. 
13. Berkovic SF, McIntosh AM, Kalnins RM, et al. Preoperative MRI predicts outcome of temporal lobectomy: an actuarial analysis Neurology 1995;45:1358-1363.

14. Garcia PA, Laxer KD, Barbaro NM, Dillon WP. Prognostic value of qualitative magnetic resonance imaging hippocampal abnormalities in patients undergoing temporal lobectomy for medically refractory seizures. Epilepsia 1994;35:520-524.

15. Jack CR Jr., Trenerry MR, Cascino GD, Sharbrough FW, So EL, O'Brien PC. Bilaterally symmetric hippocampi and surgical outcome Neurology 1995;45:1353-1358.

16. Prevedello DM, Sandmann MC, Ebner A. Prognostic factors in mesial temporal lobe epilepsy surgery. Arq Neuropsiquiatr 2000;58:207-213.

17. Kobayashi E, Lopes-Cendes I, Guerreiro CA, Sousa SC, Guerreiro $\mathrm{MM}$, Cendes F. Seizure outcome and hippocampal atrophy in familial mesial temporal lobe epilepsy. Neurology 2001;56:166-172.

18. Kuzniecky RI, Jackson GD. Magnetic resonance in epilepsy. New York: Raven Press, 1995.

19. Bengzon ARA, Rasmussen T, Gloor P, Dussault J, Stephens M. Prognostic factors in the surgical treatment of temporal lobe epileptics. Neurology 1968;18:17-31.

20. Falconer MA, Serafetinides EA, Corselis JAN. Etiology and pathogenesis of temporal lobe epilepsy. Arch Neurol 1964;10:233-248.

21. Gilliam F, Bowling S, Bilir E, et al. Association of combined MRI, interictal EEG, and ictal EEG results with outcome and pathology after temporal lobectomy. Epilepsia 1997;38:1315-1320.
22. Abou-Khalil B, Andermann E, Andermann F, Olivier A, Quesney LF. Temporal lobe epilepsy after prolonged febrile convulsions: excellent outcome after surgical treatment. Epilepsia 1993;34:878-883.

23. Cascino GD, Trenerry MR, So EL, et al. Routine EEG and temporal lobe epilepsy - relation to long-term EEG monitoring, quantitative MRI, and operative outcome. Epilepsia 1996;37:651-656.

24. Salanova V, Markand ON, Worth R. Clinical characteristics and predictive factors in 98 patients with complex partial seizures treated with temporal resection. Arch Neurol 1994;51:1008-1013.

25. Wyler AR, Hermann BP, Somes G. Extent of medial temporal resection on outcome from anterior temporal lobectomy: a randomized prospective study. Neurosurgery 1995;37:982-990.

26. Germano IM, Poulin N, Olivier A. Reoperation for recurrent temporal lobe epilepsy. J Neurosurg 1994;81:31-36.

27. Spencer DD, Spencer SS, Mattson RH, Williamson PD, Novelly RA. Access to the posterior medial temporal lobe structures in the surgical treatment of temporal lobe epilepsy. Neurosurgery 1984;15:667-671.

28. Wennberg R, Arruda F, Quesney LF, Olivier A. Preeminence of extrahippocampal structures in the generation of mesial temporal seizures: evidence from human depth electrode recordings. Epilepsia 2002;43: 716-726.

29. McKhann GM, Schoenfeld-McNeill J, Born DE, Haglund MM, Ojemann GA. Intraoperative hippocampal electrocorticography to predict the extent of hippocampal resection in temporal lobe epilepsy surgery. J Neurosurg 2000;93:44-52. 